\title{
Tuberculosis among School Age (6 - 18 Years) Children Seen in University of Port Harcourt Teaching Hospital: A Need for Effective School Health Services
}

\author{
Balafama A. Alex-Hart, Nsirimobu I. Paul*, Rosemary O. Ugwu \\ University of Port Harcourt Teaching Hospital, Port Harcourt, Nigeria \\ Email: balaalexhart@ymail.com, *nsypaul@yahoo.com
}

How to cite this paper: Alex-Hart, B.A., Paul, N.I. and Ugwu, R.O. (2019) Tuberculosis among School Age (6 - 18 Years) Children Seen in University of Port Harcourt Teaching Hospital: A Need for Effective School Health Services. Journal of Tuberculosis Research, 7, 109-117.

https://doi.org/10.4236/jtr.2019.72010

Received: May 26, 2019

Accepted: June 27, 2019

Published: June 30, 2019

Copyright $\odot 2019$ by author(s) and Scientific Research Publishing Inc. This work is licensed under the Creative Commons Attribution International License (CC BY 4.0).

http://creativecommons.org/licenses/by/4.0/

\begin{abstract}
Introduction: Tuberculosis (TB) still causes significant morbidity and mortality amongst adults and children despite all the efforts which have been put into the control of the disease. However, the prevalence of the disease in school age children is unknown because of scarcity of TB screening surveys in Nigerian schools. The aim of this study was to evaluate the proportion of school age children treated for TB in the Directly Observed Treatment Short Course (DOTS) clinic of University of Port Harcourt Teaching Hospital (UPTH). Methods: The records of all children 6 to 18 years who were treated in the DOTS clinic from 2011 to 2014 were reviewed. Information sought included age, sex, sputum Acid Fast Bacillus (AFB) status, Human Immunodeficiency Virus (HIV) status and treatment outcome. Results: One hundred and forty children aged 6 to 18 years were treated in the University Port Harcourt Teaching Hospital DOTS clinic, representing 41.79\% of childhood TB cases seen over the study period. Seventy one $(50.71 \%)$ patients were males and $69(49.29 \%)$ were females. Their mean age was $12 \pm 3.86$. Thirty-one $(22.14 \%)$ had smear positive TB. Sputum smear positivity was commonest (54.84\%) among those who were 16 years and above compared to the other age groups and this is statistically significant $\left(\mathrm{x}^{2}=17.72, \mathrm{p}=0.001\right)$. Forty-one (35\%) patients were HIV positive and 6 (4.29\%) were positive for both HIV and AFB. Ninety (64.29\%) patients recovered fully following treatment, 48 (34.29\%) were referred to other DOTS centres and $2(1.43 \%)$ died. Gender, age group, AFB and HIV status showed no relationship with treatment outcome. Conclusion: School age children 6 to 18 years made up a large proportion of childhood TB cases seen within the study period in the DOTS clinic. More than one third of them were HIV/TB co-infected. An effective School
\end{abstract}


Health Services should be established in schools in Port Harcourt to curb the spread of TB and other communicable diseases within the schools.

\section{Keywords}

Tuberculosis, School Age, University of Port Harcourt Teaching Hospital

\section{Introduction}

One of the targets of the Sustainable Development Goals (SDGs) adopted by the United Nations in 2015 is to end the global tuberculosis epidemic [1]. Despite all efforts and resources which have been put into the control of the disease, TB still causes significant morbidity and mortality globally [1]. It is one of the top ten causes of death worldwide and the leading cause of death from a single infectious agent [2], causing more death globally than the Human Immunodeficiency Virus (HIV) [2]. According to the World Health Organisation (WHO), in 2017, TB caused 1.3 million deaths among HIV negative people and 300,000 among HIV positive people [2]. Also in the same year, an estimated 10 million individuals developed TB disease globally and $87 \%$ of them resided in 30 high TB burdened countries mostly in Asia and Africa [2]. Incidentally, most of these high TB burdened countries, especially the ones in Sub-Saharan Africa also have a high HIV burden [2], signifying that HIV is the driver of the TB epidemics in these countries [2]. Children accounted for $10 \%$ of the global 10 million TB cases in 2017 and $15 \%$ of the global TB deaths [2].

Nigeria is one of the 30 high TB burdened countries which have contributed significantly to the global childhood TB epidemic [3]. In 2017, an estimated 57,000 children developed TB, representing $13.6 \%$ of the estimated 418,000 new TB cases in Nigeria [4]. Children acquire the disease by inhaling the TB bacteria released by an adult with open TB [3]. A study done in Nigeria amongst children living with adults with tuberculosis at a TB referral hospital revealed a TB prevalence rate of $68 \%$ among the children living with adult TB patients in the hospital and 50.6\% prevalence among children living within the hospital environment [5]. Childhood TB is therefore a good indicator of ongoing transmission of the disease within the community [6]. The source of infection for children is usually close family members with open TB, who have been coughing forcefully [3]. Older children may acquire the disease from close contacts in schools. However, the prevalence rate of TB among the children of school age in Nigeria is unknown. Several studies from different countries have reported on the high prevalence of latent TB and TB disease among school children and staff. Middelkoop et al. reported a TB prevalence rate of $45 \%$ among secondary school children in a high TB and HIV burdened community in South Africa following a school based screening for TB [7]. Dorjee et al., reported a latent TB infection prevalence of $18 \%$ and $54 \%$ among secondary school children and staff respec- 
tively of a community school in India [8]. These researchers equally found 46 cases of TB disease and one case of extensive drug resistant TB amongst the children [8]. Though these studies were done outside Nigeria, they however showed the magnitude of the global childhood TB burden among school children and the need to include the school communities in the active TB case finding.

Little is known about the burden of tuberculosis in school age children in $\mathrm{Ni}$ geria because of paucity of school based TB screening surveys in Nigeria. Furthermore, TB diagnosis in school age children is either aggregated with childhood TB ( 0 to 14 years) or adult TB (15 years and above) with limited information specific to the school age group. This study was therefore aimed at evaluating the proportion of childhood TB cases that were seen in school age children attending the DOTS clinic in the University of Port Harcourt Teaching Hospital.

\section{Materials and Methods}

This was a cross sectional, retrospective, hospital based study conducted in the DOTS clinic in the University of Port Harcourt Teaching Hospital (UPTH). UPTH is a tertiary hospital in Port Harcourt, Rivers State, in Southern Nigeria. It is a referral hospital for the primary and secondary health facilities in Rivers State and the neighbouring states. The hospital has one of the DOTS clinics in Rivers State. The DOTS clinic handles both adult and childhood TB cases. The study was done over a four week period from first to $31^{\text {st }}$ August 2018. Clinical records of children aged 6 years to 18 years, who received anti-TB treatments in the DOTS clinic from first January 2011 to $31^{\text {st }}$ December 2014 were reviewed. This period was chosen because it predates the era of XpertMTB/RIF as a diagnostic tool for TB in UPTH. The Information sought included age, sex, sputum smear positivity, HIV status, duration of treatment and treatment outcome. The clinic followed the National Tuberculosis and Leprosy Control Programme and the WHO directly observed treatment short course strategy. Diagnosis of tuberculosis was based on sputum smear positivity, clinical and radiological diagnosis. Children diagnosed with TB received Rifampicin, Isoniazid, Ethambutol and Pyrazinamide for 2 months, followed by 4 months of Rifampicin and Isoniazid.

\section{Data Analysis}

Data was fed into excel spread sheet and analysed using SPSS version 20 statistical software. Data was analysed using descriptive statistics and results presented as proportions. Chi-square test was used to show the association between sputum AFB positivity, age group and gender. Chi-square test was also used to show the association between gender, HIV sero-positivity, AFB status and treatment outcome. Only p value less than 0.05 was regarded as significant.

\section{Results}

One hundred and forty children aged 6 to 18 years were treated in the UPTH DOTS clinic, representing $41.79 \%$ of childhood TB cases seen over the study pe- 
riod. There were 71 (50.71\%) males and 69 (49.29\%) females, with male: female ratio of 1.03:1. Their mean age was $12.06 \pm 3.86$. Fifty five $(39.29 \%)$ belonged to the age group 6 to 10 years, $49(35.0 \%) 11$ - 15 years and $36(25.71 \%)$ were 16 to 18 years. The sputum of $31(22.14 \%)$ patients was positive for AFB. Table 1 showed the association between age group and gender with sputum AFB status. Sputum AFB positivity was significantly highest (54.84\%) among the age group 16 years and beyond, whilst the age group 6 years to 10 years were more sputum AFB negative and this was statistically significant $\left(x^{2}=17.72, p\right.$-value 0.001$)$. There was no statistically significant difference between the number of males and females who were smear positive $\left(\mathrm{x}^{2}=0.10, \mathrm{p}=0.751\right)$.

Forty-nine $(35.0 \%)$ patients tested positive for the Human Immunodeficiency virus. Six (4.29\%) patients were positive for both HIV and AFB. Ninety (64.29\%) patients recovered following treatment, 48 (34.29\%) were referred to other DOTS Centres to continue treatment and 2 (1.43\%) died.

Association between age group and treatment outcome showed that out of the $90(64.29 \%)$ patients who recovered fully following treatment, 39 (43.33\%) belonged to the 6 - 10 years age group, 35 (38.89\%) were 11 - 15 years and 17 (17.78\%) were 16 years and above. Out of the 48 (34.29\%) children who were referred, $16(33.33 \%)$ were 6 - 10 years, 13 (27.08\%) were 11 - 15 years and 19 $(39.58 \%)$ were 16 years and above. Out of the $2(1.43 \%)$ patients who died, 1 (50\%) belonged to the 11 - 15 years age group and the other 1 (50\%) belonged to the age group 16 years and above. These differences were however not statistically significant $\left(\mathrm{x}^{2}=9.22, \mathrm{p}=0.06\right)$.

Relationship between AFB status and treatment outcome showed that out of $90(64.29 \%)$ patients who recovered fully with treatment, 17 (18.89\%) were sputum smear positive, while $73(81.11 \%)$ were smear negative. Out of the 48 (34.29\%) patients who were referred, 14 (29.17\%) were smear positive and 34 (70.83\%) were smear negative. The $2(1.43 \%)$ patients who died were both sputum smear negative. These observed differences were not statistically significant $\left(\mathrm{x}^{2}=2.50, \mathrm{p}=0.29\right)$.

Table 1. Association between age group, gender and AFB status.

\begin{tabular}{ccccc}
\hline \multirow{2}{*}{ AGE GROUP } & \multicolumn{2}{c}{ AFB STATUS } & TOTAL & $\begin{array}{c}\text { Chi-square } \\
\text { (p-value) }\end{array}$ \\
\cline { 2 - 3 } & POSITIVE (\%) & NEGATIVE (\%) & & $17.72(0.001)^{*}$ \\
\hline $6-10$ & $7(22.58)$ & $48(44.04)$ & $55(39.29)$ & \\
$11-15$ & $7(22.58)$ & $42(38.53)$ & $49(35.0)$ & \\
$\geq 16$ & $17(54.84)$ & $19(17.43)$ & $36(25.71)$ & \\
TOTAL & $31(22.1)$ & $109(77.9)$ & $140(100)$ & \\
GENDER & & & & \\
Male & $17(54.84)$ & $54(49.54)$ & $71(50.71)$ & $0.10(0.751)$ \\
Female & $14(45.16)$ & $55(50.46)$ & $69(49.29)$ & \\
TOTAL & $31(22.1)$ & $109(77.9)$ & $140(100)$ & \\
\hline
\end{tabular}


Relationship between HIV status and treatment outcome showed that out of the $90(64.29 \%)$ patients who recovered fully with treatment, 30 (33.33\%) were HIV positive while $60(66.67 \%)$ were HIV negative. Out of the $48(34.29 \%)$ who were referred out, 18 (37.50\%) were HIV positive, while 30 (62.50\%) were HIV negative. Out of the $2(1.43 \%)$ who died, 1 (50\%) was HIV positive and the other (50\%) was HIV negative. These observed differences were not statistically significant $\left(\mathrm{x}^{2}=0.44, \mathrm{p}=0.803\right)$.

The association between HIV and Smear positivity with treatment outcome showed that out of the 90 (64.29\%) patients who recovered fully following treatment, $2(2.22 \%)$ were both sputum smear and HIV positive, while $88(97.78 \%)$ were negative for both HIV and sputum smear. Out of the 48 (34.29\%) patients who were referred out, 4 (8.33\%) were positive for both sputum smear and HIV, while $44(91.67 \%)$ were negative for both sputum smear and HIV. The $2(1.42 \%)$ patients who died were negative for both sputum smear and HIV. These differences were not statistically significant $\left(\mathrm{x}^{2}=2.94, \mathrm{p}=0.23\right)$.

\section{Discussion}

We observed that more than two fifth (41.79\%) of the childhood TB cases treated in the DOTS clinic of UPTH over the study period involved children 6 to 18 years, an age group mostly found in primary and secondary schools in Nigeria [9]. The fact that this is a hospital based data is worrisome because it means that the situation may be worse within the communities. Nigeria ranked third among the top ten countries responsible for $80 \%$ of the global under reporting of TB cases [2]. This is probably because majority of the cases do not reach the health facilities or when they do, they are underdiagnosed [2].

We equally observed that almost a quarter (22.14\%) of the children have smear positive tuberculosis, which is higher than the $16.83 \%$ reported by Nwachukwu et al. [10] in Eastern Nigeria, though the previous study was a much larger study, involving both adults and children. It is lower than the $37.1 \%$ reported by Ogbudebe et al. [6] in Western Nigeria. However, in this previous study the $37.1 \%$ comprised of those who were diagnosed using either sputum microscopy or GeneXpert. The fact that $22.14 \%$ of the children were sputum smear positive and that the positive smears were most commonly found among those who were 16 years and above (54.84\%) have serious implications for the control of tuberculosis in Nigeria. These adolescents represented a reservoir for further spread of the disease to family members and to other children within the school because they were likely to have had cavities on chest x-ray and were highly infectious [11]. The long duration of stay in school (about 8 hours daily for day students), more frequent exposures (meeting 5 days in a week) and close proximity in the classroom due to over crowdedness[12] will enhance the spread of the TB bacillus. The End TB Strategy milestone for 2025 calls for a reduction in number of TB deaths by $75 \%$ and TB incidence by $50 \%$ [13]. For these milestones to be achieved, the TB diagnosis, treatment and preventive services must 
be provided for the school communities [2].

HIV co-infection is said to be the most powerful risk factor for progression from TB infection to active disease due to progressive weakening of the immune system [13].This study revealed a TB/HIV co-infection rate of $35 \%$, which is higher than the $14.9 \%, 29 \%$ and $22.7 \%$ in three previous studies in Nigeria [6] [14] and South Africa [15]. Rivers State was the state with the highest HIV prevalence (15.2\%) in 2012 (the period under consideration in this study) and states in South West Nigeria had very low prevalence rates, ranging from $0.2 \%$ to $4.3 \%$ [16]. It is therefore not surprising that the TB/HIV co-infection rate in this study is higher than those reported in the two previous studies done in South Western Nigeria with low HIV prevalence [16]. The authors however have no explanation for the lower rate of TB/HIV co-infection in the South African study compared to this present study since South Africa has a higher HIV burden than Nigeria [17].

Patients with TB/HIV co-infection are said to have fewer bacilli in their sputum than the HIV uninfected patients [18], making diagnosis of TB very difficult with bacteriological tests, especially the sputum smear microscopy. It is therefore not surprising that in this study only $4.29 \%$ of the patients were both sputum smear positive and HIV positive. This difficulty in diagnosing TB in HIV positive patients is probably why WHO endorsed the use of GeneXpert-Rif for the diagnosis of TB and rifampicin resistance among HIV patients with clinical suspicion of TB to enhance early diagnosis of TB and commencement of anti TB treatment [19] [20]. Unfortunately, diagnosis of TB in UPTH was done mostly clinically, radiologically and with sputum microscopy due to unavailability of GeneXpert at the period under consideration.

More than two third of the patients in this study recovered fully following treatment, probably due to early presentation in the health facility, early diagnosis and commencement of appropriate treatment. Other studies in Nigeria also reported high cure rates following treatment with anti TB medications [6] [15]. Contrary to the report of a previous study that male sex and HIV seropositivity were associated with unsuccessful treatment outcome [6], our study showed that these factors have no association with treatment outcome. However, we observed that majority of those who recovered fully following treatment were HIV negative $(66.67 \%)$, sputum smear negative $(81.11 \%)$ and negative for a combination of HIV and smear microscopy (97.78\%). These observations were not statistically significant, probably because the outcome also included those who were referred out to other DOTS centres due to proximity to their places of residence. This study recorded only 2 deaths, among males with smear negative TB. One of them was HIV positive and the other negative. Perhaps late presentation at the health facility and late commencement of appropriate medications may have been responsible for these deaths, however these facts were not considered in this study.

The result of this study has revealed the absolute necessity for the establishment of an effective School Health Services in both primary and secondary schools in Nigeria. This school based health services deals with such issues as 
first aid, medical emergencies and detection of contagious diseases such as TB that could spread within the school [21]. Once TB is detected and early and appropriate treatment instituted, survival is enhanced. Early detection can be done through both pre-school entry and in-school medical exams.

\section{Conclusion}

In conclusion, a large proportion of childhood TB patients seen in the DOTS clinic of UPTH belonged to the school age and more than one third of them have HIV/TB co-infection. Smear positive TB was commoner among the older age group. There was a high rate of treatment success.

\section{Recommendations}

1) Effective school health services should be established in all our primary and secondary schools in Port Harcourt to aid early detection of these contagious diseases and prompt commencement of treatment.

2) Pre-school entry medical exams should be made compulsory in all the primary and secondary schools in Port Harcourt.

3) Nationwide school screening for TB should be done to detect both the latent infection and $\mathrm{TB}$ disease. This will improve our TB case finding and reporting.

\section{Limitations of the Study}

This study was retrospective in nature and one major disadvantage of the retrospective study is that it uses existing data that have been recorded for reasons other than research. The other limitation of the study is that diagnosis of TB was done using smear microscopy, clinical and radiological methods only. Sputum culture and GeneXpert were not done. It is possible that some cases may have been misdiagnosed. Thirdly, this study could not record the presence or absence of drug resistant TB because as already stated XpertMTB/RIF was not available in the hospital during the period under consideration.

\section{Acknowledgements}

We wish to acknowledge the staff of the DOTS clinic of University of Port Harcourt Teaching Hospital for their support and cooperation.

\section{Conflicts of Interest}

The authors declare no conflicts of interest regarding the publication of this paper.

\section{References}

[1] World Health Organization (WHO) (2016) Global Tuberculosis Report 2016. WHO, Geneva.

[2] World Health Organization (WHO) (2018) Global Tuberculosis Report 2018. 
WHO, Geneva.

[3] Kanabus, A. (2018) Information about Tuberculosis. GHE. http://www.tbfacts.org

[4] World Health Organization (2017) Nigeria TB Profile. https://extranet.who.int/sree/Reports?op=Replet\&name=\%2FWHO_HQ_Reports\%2F G2\%2FPROD\%2FEXT\%2FTBCountryProfile\&ISO2=NG\&LAN=EN\&outtype $=$ html

[5] Ewa, A.U., Essiet, D.F. and Monu, S.T.U. (2015) Tuberculosis in Children Living amongst Adults with Tuberculosis and Leprosy Referral Hospital, Eku, Nigeria. Journal of Tuberculosis Research, 3, 80-89. https://doi.org/10.4236/jtr.2015.33013

[6] Ogbudebe, C.L., Adepoju, V., Ekerete-Udofia, C., Abu, E., Egesemba, G. and Chukwueme, M. (2018) Childhood Tuberculosis in Nigeria: Disease Presentation and Treatment Outcomes. Health Services Insights, 11, 1-7. https://doi.org/10.1177/1178632918757490

[7] Middelkoop, K., Bekker, L.G., Liang, H., Aquino, L.D.H., Sebastianm E., Myer, L. and Wood, R. (2011) Force of Tuberculosis Infection among Adolescents in a High HIV and TB Prevalence Community: A Cross-Sectional Observation Study. BMC Infectious Diseases, 11, 156. https://doi.org/10.1186/1471-2334-11-156

[8] Dorjee, K., Topgyal, S., Dorjee, C., Tsundue, T., Namdol, T., Tsewang, T., et al. (2018) High Prevalence of Active and Latent Tuberculosis in Children and Adolescents in Tibetan Schools in India: The Zero TB Kids Initiative in Tibetan Refugee Children. Clinical Infectious Diseases, ciy987. https://doi.org/10.1093/cid/ciy987

[9] Huebler, F. (2006) Age and Level of Education in Nigeria. International Education Statistics.

https://huebler.blogspot.com/2005/12/age-and-level-of-education-in-nigeria.html

[10] Nwachukwu, N.C., Kanu, O.I. and Okereke, H.C. (2009) Epidemiology of Pulmonary Tuberculosis in Some Parts of Abia State, Federal Republic of Nigeria. Asian Journal of Epidemiology, 2, 13-19. https://doi.org/10.3923/aje.2009.13.19

[11] World Health Organization (WHO) (2018) Roadmap towards Ending TB in Children and Adolescents. 2nd Edition, Geneva. https://apps.who.int/iris/bitstream/handle/10665/275422/9789241514798-eng.pdf?u $\underline{a}=1$

[12] Olaleye, F.O., Ajayi, A., Oyebola, O.B. and Ajayi, O.A. (2017) Impact of Overcrowded Classroom on Academic Performance of Students in Selected Public Secondary Schools in Surelere Local Government of Lagos State, Nigeria. International Journal of Higher Education and Research, 7, 110-132.

[13] World Health Organization. The End TB Strategy. https://www.who.int/tb/End_TB_brochure.pdf?ua=1

[14] Adejumo, O.A., Daniel, O.J., Adebayo, B.I., Adejumo, E.N., Jaiyesimi, E.O., Akang, G. and Awe, A. (2016) Treatment Outcomes of Childhood TB in Lagos, Nigeria. Journal of Tropical Pediatrics, 62, 131-138. https://doi.org/10.1093/tropej/fmv089

[15] Budgell, E.P., Evans, D., Leuner, R., Long, L. and Rosen, S. (2018) The Costs and Outcomes of Pediatric Tuberculosis Treatment at Primary Health Care Clinics in Johannesburg, South Africa. South African Medical Journal, 108, 423-431. https://doi.org/10.7196/SAMJ.2018.v108i5.12802

[16] National Agency for the Control of AIDS (NACA) (2014) Federal Republic of Nigeria. Global AIDS Response: Country Progress Report. Nigeria GARPR 2014. Abuja, Nigeria.

https://www.unaids.org/sites/default/files/country/documents/NGA_narrative_repo rt_2014.pdf

[17] Statistics South Africa (2018) Statistical Release: Mid-Year Population Estimates 
2018. https://www.statssa.gov.za/publications/P0302/P03022018.pdf

[18] Getahun, H., Gunneberg, C., Granich, R. and Nunn, P. (2010) HIV Infection-Associated Tuberculosis: The Epidemiology and the Response. Clinical Infectious Diseases, 50, S201-S207. https://doi.org/10.1086/651492

[19] Padmapriyadarsini, C., Narendran, G. and Swaminathan, S. (2011) Diagnosis \& Treatment of Tuberculosis in HIV Co-Infected Patients. Indian Journal of Medical Research, 134, 850-865. https://doi.org/10.4103/0971-5916.92630

[20] World Health Organization and STOP TB Departments (2010) Roadmap for Rolling out Xpert MTB/RIF for Rapid Diagnosis of TB and MDR-TB. https://www.who.int/tb/laboratory/roadmap_xpert_mtb-rif.pdf

[21] Allensworth, D., Lawson, E. and Nicholson, L. (1997) Schools \& Health: Our Nation's Investments. National Academic Press, Washington DC. 